\title{
Perceptions of grasscutter (Thryonomys swinderianus) farmers on production technologies in the Agona West Municipality, Central Region - Ghana
}

\author{
B. Y. FOLITSE* \& S. A. MANTEAW \\ (B.Y.F \& S.A.M.: CSIR-Institute for Scientific and Technological Information, Accra) \\ *Corresponding author's email: folitse62@yahoo.com
}

\begin{abstract}
The study sought to assess the dynamics of grasscutter (Thryonomys swinderianus) Production Technologies being used in the Agona West Municipality in the Central Region of Ghana. Farmers were selected from 20 communities with the help of staff from the Department of Agriculture and were interviewed using structured questionnaires. The results revealed that though the grasscutter farmers were varied in their views, the dissemination of grasscutter technologies through video in the study area was deemed to be effective. The results of the Logistic regression model (R-Square values of 0.119 and 0.158 ) showed that the impact of the dissemination programme on the livelihoods of farmers who had adopted the grasscutter production technologies was best predicted by age, household size and level of education of farmers. The overall mean, 3.99 showed that the livelihoods of the farmers had highly been improved. The paper makes a strong case for a more participatory approach anchored on inclusive problem identification and formulation of research solution that will further ensure that problems that are targeted by research emanate from farmers. This is expected to ensure a more effective extension of research technologies to farmers and other actors along the grasscutter value chain in the area.
\end{abstract}

Keywords: Grasscutter; Production Technologies; Agona West Municipality; Central Region; Ghana.

Original scientific paper. Received 09 Jul 18; revised 26 Jul 19

\section{Introduction}

Grasscutter (Thryonomys swinderianus) is an important source of meat and is historically acknowledged to be one of the preferred sources of meat throughout Ghana and the West African Sub-Region (Falconer, 1992). The meat is cherished because of its culinary properties with demand consistently outstripping supply (Adoma, 2009). The potentials of grasscutter farming as a means of poverty alleviation, as well as its contribution to keeping environmental health, have long been recognized in Ghana (Adu, 2002). However, the impact of grasscutter farming on national development is yet to be realized. Though grasscutter farming has been practiced in Ghana for some decades now, the enterprise remains in the hands of smallholder farmers, who are generally poor and have neither the institutional nor economic power to ensure that their technology needs are met by public sector research (Anandajayasekeram, 1999). The demand for grasscutter meat in Ghana is high with its accompanying price hikes, making the prospect of grasscutter rearing very bright and encouraging either as a full-time or part-time job. Asibey and Addo

Ghana Jnl Agric. Sci. 54 (1), 47 - 55

GJAS is an Open Access Journal and distributed under the terms of the Creative Commons (CC) License [CC BY 4.0] 
(2000) in an earlier study perceived that about $80 \%$ of the rural population in Ghana depended on game meat for their dietary protein supply and that the most commonly consumed species of game meat by those living in rural areas was grasscutter. Grasscutter meat is also a delicacy in big towns and cities in Ghana such as Accra, Kumasi, Nkawkaw, Konongo, Ejisu, Anyinam, Suhum and Nsawam.

Zeba (1998) had also observed that in most developing countries, the living conditions of rural dwellers are severely affected by some basic needs such as; lack of food, poor income generation (poverty), droughts, desertification, diseases, and poor education. According to an Economic Committee of West African States (ECOWAS) report on desertification in 1993, in more than $50 \%$ of West Africans, subsistence farming supports the families for up to 9 months in the year. In the absence of appropriate technologies, funds for mechanization and a sustained supply of adequate quantities of inputs increased productivity remains a dream as shifting cultivation prevails. The farmers are very aware of the declining yields and even blame it on the disappearing forests (Adoma, 2009).

Despite a lack of defined or measurable indications for its contribution to the gross domestic product (GDP), the grasscutter subsector has been recognized as an important economic tool for rural poverty alleviation and household food and nutrition security (Adu, 2002). The grasscutter is a considerable income earner for both the small scale peri-urban or rural livestock producer in the country. It also contributes to both local and export earning of countries such as Kenya, Benin republic and Nigeria (Ntiamoah-Badu, 1997). It is known to be economically important as an agricultural pest and its meat is widely accepted by all classes of people. The smoked grasscutter could serve as a source of foreign exchange earnings when it is well packaged and exported. Grasscutter meat is cheaper to produce than most other traditional livestock and its meat is more valuable and appreciated by the local population. It has been shown that with only five mature grasscutters (four females and one male), a household is nutritionally secured for 6 months to one year (Juma \& Ondwasy, 2002). In times of drought and related calamities, grasscutter serves as a critical source of animal protein. During important occasions and ceremonies, grasscutters are heavily consumed by many households in rural and urban areas in Nigeria. Dried grasscutter meat is used to serve the elders during traditional rights such as marriages, excursion and Chieftaincy installations. This confirms that grasscutter is the favorite bushmeat species. The hair or fur is used to make decoration and the teeth are used to perform traditional card reading in place of cowries especially in the Southern part of the country.

A major challenge in the technology generation and transfer is the fact that technologies generated may not reach the intended beneficiaries. Farmers in rural areas are faced with many problems due to inadequate access to improved agricultural technologies. Accordingly, the Food and Agricultural Organization (FAO, 2001) had bemoaned this fact when it indicated that the quantum of agricultural technology information available in the Ghanaian systems developed by research institutes and faculties of agriculture in universities that were yet to reach farmers is quite gargantuan. The problem, therefore, had to do with effective dissemination of technologies about the innovations developed.

The Council for Scientific and Industrial Research, Institute for Scientific and Technological Information (CSIR- 
INSTI) in collaboration with the Agricultural Information Centre (AIC) of the Department of Agriculture in the Agona West Municipal Assembly introduced farmers to the use of grasscutter production technologies generated within the CSIR in 2006. The main aim of the programme was to enhance the generation and dissemination of agricultural technologies through the use of videos to benefit extension agents and grasscutter farmers in the Central Region of Ghana. Agona West Municipal, though a potential area for grasscutter production, has relatively low grasscutter production. Grasscutter farmers rely mainly on their traditional techniques, skills, knowledge, and practices to hunt for grasscutters. The muchexpected increase in grasscutter production was yet to be attained, despite the numerous improved agricultural technologies that had been developed by the research institutes and universities.

It is against this background that this study sought to assess perceptions regarding the impact of the use of grasscutter production technologies on the livelihoods of farmers in the Agona West Municipal Assembly in the Central Region of Ghana by;

(1) Examining the socio-demographic characteristics of grasscutter farmers;

(2) Identifying the effect of the technologies on grasscutter farmers' production,

(3) Assessing the extent to which the socio-demographic characteristics of grasscutter farmers influence the use of grasscutter production technologies

(4) Determining the impact of grasscutter production technologies on grasscutter farmers' livelihoods.

\section{Materials and Methods}

Area of Study:

The Agona West Municipal is located in the eastern portion of the Central Region. It has a total land area of 540-square kilometers and a population of 160,000 (Ghana Districts, 2006). The municipality lies within latitudes $5^{\circ} 30^{\prime}$ and $5^{\circ} 50^{\prime} \mathrm{N}$ and longitudes $0^{\circ} 35^{\prime}$ and $0^{\circ} 55 \mathrm{~W}$. The area is bounded to the East and West by Effutu Municipal and Asikum/Odoben/Brakwa Districts respectively. The municipality shares a border to the northeast with Akim West Municipal, to the northwest with Brim-South District and the South, with Gomoa District. The vegetation falls within the moist semi-deciduous forest zone and has a lot of valuable trees suitable for timber processing (Ghana Districts, 2006). As a result of environmental degradation caused by farming and the activities of logging companies, most of the original forest is being reduced to a secondary forest (Ghana Districts, 2006). Agriculture is the mainstay of the people's economy. Agricultural products produced in commercial quantities in the area include fruits, grains, and tuber crops.

\section{Research design:}

The Department of Agriculture in the Agona West Municipal Assembly has no up-to-date information on the number of grasscutter farmers. Purposive sampling was therefore used to select grasscutter farmers in the study area who had received training on various technologies of grasscutter production. Farmers were selected from 20 communities with the help of staff from the Department of Agriculture. Random sampling technique was used to select 140 farmers made up of 110 males and 30 females within 20 communities from the Agona West Municipality. 


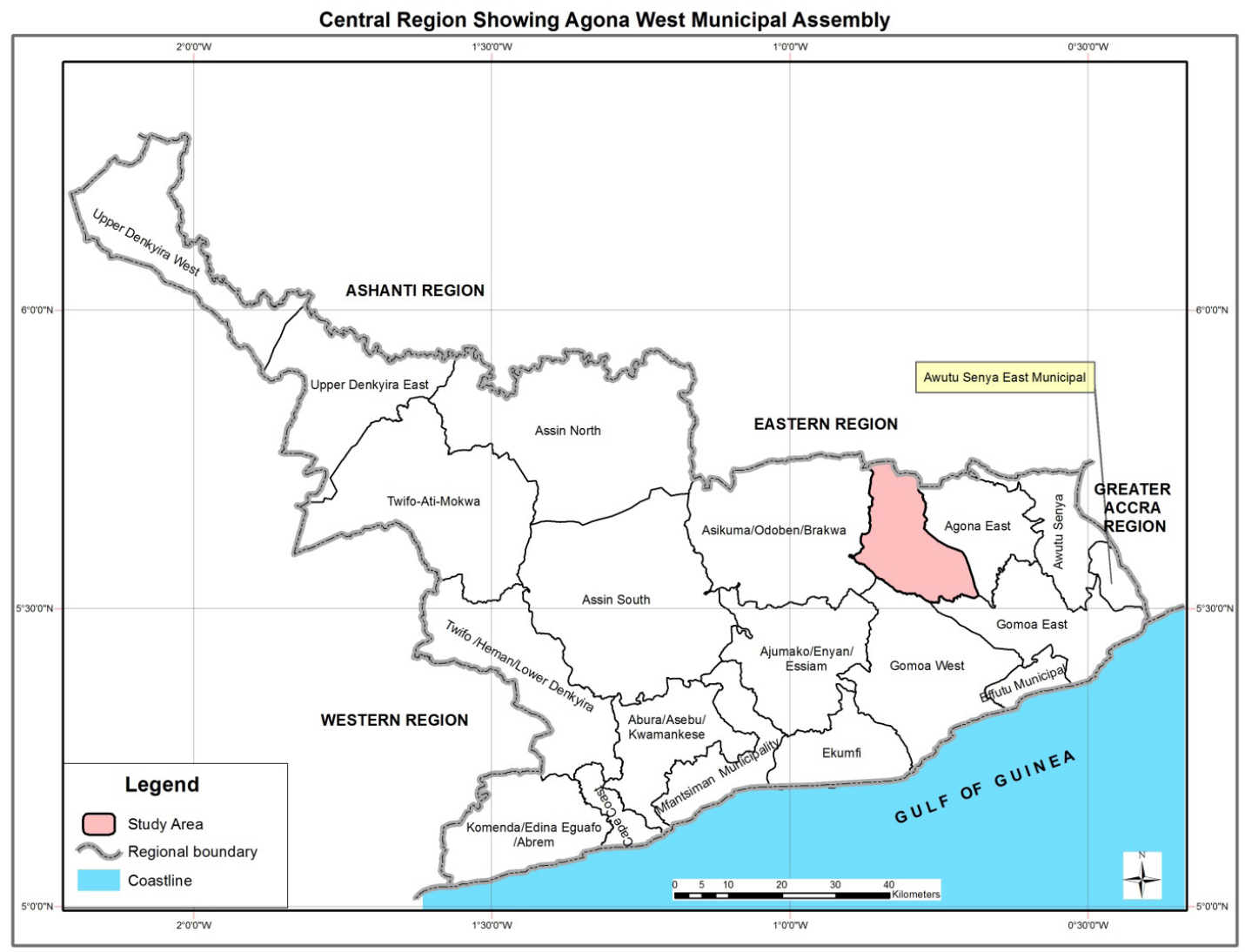

Fig. 1: Map of the study area

An interview schedule made up of closed-ended questions was used to elicit information from the 140 selected grasscutter farmers. Descriptive statistics such as means, frequencies and percentages were used to analyze the result. Inferential statistics used was Logistic Regression to establish the relationship between grasscutter farmers' socio-economic characteristics and use of Grasscutter production technologies. The Statistical Package for the Social Sciences (SPSS) software version 16 was used in the analysis of the data.

\section{Results and Discussion}

Socio-demographic Characteristics of Grasscutter farmers

The results (Table 1) revealed that majority of the grasscutter farmers were males of active farming age of 21 to 40 years. This result agreed with that of Daudu, Igbashal, and Ejigonoja (2005) which gave the age range of $36-45$ years as the most prevalent among farmers in Benue State, Nigeria. This is an advantage for increased investment and improved technology utilization and hence 
innovativeness. With respect to the marital status of the grasscutter farmers, more than half of the grasscutter farmers were married, while about a third indicated that they were single. The Table indicates that about twothirds of the grasscutter farmers had 6-10 household members. The implication of this is that more family labour will be readily available since relatively large household size has been reported by Igben (1988) to be an obvious advantage in terms of farm labour supply. Information about the educational level of grasscutter farmers revealed that the highest proportion of the grasscutter farmers belonged to Junior High School and this was followed by primary education and secondary education in that other. This showed that most of the grasscutter farmers were literate enough to comprehend the technologies on grasscutter production.

TABLE 1

Socio-Demographic Characteristics of Grasscutter farmers

\begin{tabular}{lcr}
\hline Variable & Frequency & Percentage \\
\hline Sex & & $\mathbf{( \% )}$ \\
Male & 110 & 78.6 \\
Female & 30 & 21.4 \\
\hline Variable & Frequency & $\begin{array}{r}\text { Percentage } \\
\text { Age }\end{array}$ \\
$<20$ & & $\mathbf{( \% )}$ \\
$21-30$ & 7 & 5.0 \\
$31-40$ & 40 & 28.6 \\
$41-50$ & 41 & 29.3 \\
51 and above & 34 & 24.3 \\
Marital Status & 18 & 12.9 \\
Single & & \\
Married & 47 & 33.6 \\
Divorced & 89 & 63.6 \\
Family size & 4 & 2.8 \\
$1-5$ & & \\
& 52 & 37.1
\end{tabular}

$6-10$

$11-15$

26

44.3

Level of education

No formal education

22

Primary education $\quad 30$

15.7

Junior High School

Secondary education

61

21.4

43.6

27

19.3

The effect of technologies on production

Farmers were asked to provide their perceptions regarding the effect of the grasscutter technologies disseminated. Results presented in Table 2 indicated that grasscutter farmers perceived technology on animal housing (mean $=4.11)$, feeding (mean $=4.22$ ), animal health (4.09), control of animal diseases (4.09) and control of pest (4.18) of grasscutter to be effective to grasscutter production. Adoption of technology is the decision to make full use of a new idea as the best course of action available and involves a change in the orientation and behaviour of the farmer (Akubuilo, 1982). Though grasscutter farmers were varied in their views, the dissemination of grasscutter technologies through video in the catchment area was deemed to be effective.

TABLE 2

Effect of the technologies on grasscutter farmers'production

\begin{tabular}{lccc}
\hline Effectiveness & Number & Mean & SD \\
\hline $\begin{array}{l}\text { Sanitation in grass- } \\
\text { cutter housing }\end{array}$ & 28 & 3.90 & 0.96 \\
$\begin{array}{l}\text { Housing of grass- } \\
\text { cutters }\end{array}$ & 47 & 4.11 & 1.18 \\
$\begin{array}{l}\text { Feeding grasscutters } \\
\begin{array}{l}\text { Grasscutter breeding } \\
\text { practices }\end{array}\end{array}$ & 43 & 4.22 & 0.82 \\
$\begin{array}{l}\text { Grasscutter health } \\
\begin{array}{l}\text { Control of grasscutter } \\
\text { diseases }\end{array}\end{array}$ & 30 & 4.69 & 1.33 \\
\end{tabular}




\begin{tabular}{llll}
$\begin{array}{l}\text { Control of Pest of } \\
\text { grasscutters }\end{array}$ & 43 & 4.18 & 0.82 \\
\hline
\end{tabular}

Source: Field data, 2018. Multiple responses Scale: Scale: $0=$ cannot tell, $1=$ not very effective, $2=$ not effective, $3=$ moderately effective, $4=$ effective, $5=$ very effective

The extent to which the Socio-economic Characteristics of Grasscutter farmers Influence the use of grasscutter production technologies

Age, household size and level of education were significant socio-demographic characteristics that predicted the use of grasscutter production technologies disseminated through the video programme at the 0.05 alpha level (Table 3). The Cox Snell R- Square and Nagelkerke R- Square (pseudo R Squares) values of 0.119 and 0.158 which are the measures of goodness of fit implied that 12 to $16 \%$ of the variation in grasscutter farmers' use of grasscutter production technologies disseminated by video was explained by age, household size and level of education. The Chi-square test of the regression model was significant at alpha level 0.01. This means that these variables in the model have significant influence on grasscutter farmers' use of grasscutter production technologies disseminated through video. These results are in line with Tiamiyu Akintola and Rahji (2009), who in a similar study, concluded that technology use was affected significantly by grasscutter farmers' age, family size and level of education. Asiabaka and Owens (2002) reported that a socio-economic demographic characteristic of the grasscutter farmers had interacting influences on the frequency of use of agricultural technologies. Knowledge of how these factors influence information-seeking behaviour of grasscutter farmers is important for improving access and usage of information in rural areas.
The logit model for use of grasscutter production technologies disseminated through video programme,

$$
\mathrm{Z}=-0.739+0.442(\text { Sex })_{1}+0.068(\text { Age })_{2}
$$

- 0.394(Education $)_{3}+0.189$ (Marital status) $)_{4}-$ 0.245 (Household size) $)_{5}-0.041$ (Family size) 6

\section{TABLE 3}

Logistic Regression Showing the Relationship between grasscutter farmers' Socio-demographic Characteristics and use of Grasscutter production technologies

\begin{tabular}{lcccc}
\hline $\begin{array}{l}\text { Explanatory } \\
\text { variables }\end{array}$ & $\begin{array}{c}\beta \\
\text { coefficient }\end{array}$ & Wald & P-value & $\begin{array}{c}\text { Odd } \\
\text { Ratio }\end{array}$ \\
\hline Constant & $0-.739$ & 1.425 & 0.233 & 2.094 \\
Sex & 0.442 & 3.453 & 0.063 & 0.642 \\
Age & 0.068 & 11.442 & $0.001^{* *}$ & 0.934 \\
$\begin{array}{l}\text { Education } \\
\text { Marital Status }\end{array}$ & $0-.394$ & 2.112 & 0.146 & 1.483 \\
$\begin{array}{l}\text { Household } \\
\text { size }\end{array}$ & $0-.189$ & 0.310 & 0.577 & 0.828 \\
$\begin{array}{l}\text { Level of edu- } \\
\text { cation }\end{array}$ & $0-.041$ & 4.050 & $0.044^{*}$ & 1.042 \\
\hline
\end{tabular}

\section{Model}

Summary

\section{Cox Snell R-}

Square

0.119

Nagelkerke

R-Square

0.158

Chi- square $\quad 50.083^{* *}$

Sig. (p - value) $\quad 0.000^{* *}$

**; *; Significant at 0.01 and 0.05 alpha

levels respectively. Field survey, 2018

The impact of grasscutter production technologies on grasscutter farmers' livelihoods

To examine the impact of grasscutter production technologies on the livelihood capital of grasscutter farmers in the area of study, five areas of livelihood namely natural, human, physical, financial and social capital were 
considered. Livelihood capitals are critical to the survival of people in response to stresses and shock while not compromising the natural resource base (Ansoms \& McKay, 2010). Natural capital consists of land, water and biological resources such as trees, pasture and wildlife. Physical capital is that created by economic production. It includes infrastructure such as roads, irrigation works, electricity supply and reticulated water and also producer goods such as machinery. Human capital is constituted by the quantity and quality of labour available. At household level therefore, it is determined by household size, education, skills and health of household members. Financial capital consists of stocks of money or other saving in liquid form. In this sense, it not only include financial assets such as pension rights but also includes easily-disposed assets such as livestock which in other senses may be considered as natural capital. Social capital includes any assets such as rights or claims that are derived from membership of a group. This includes the ability to call on friends or for help in times of need, support from trade or professional associations (e.g. farmers' associations) and political claims on chiefs or politicians to provide assistance (Scoones,1998). Generally, grasscutter farmers perceived high level of impact (Mean $=3.99, \mathrm{SD}=0.77$ ) of the programme on their livelihoods. Grasscutter farmers perceived that grasscutter production technologies disseminated through video had highly improved their livelihood in terms of natural capital (Mean=3.75; $\mathrm{SD}=1.29)$ and their physical capital (Mean=4.05; $\mathrm{SD}=1.14$ ). The impact of grasscutter production technologies on financial capital (Mean=4.02: $\mathrm{SD}=1.02)$ and human capital (Mean=3.87: $\mathrm{SD}=1.27$ ) was recorded. This result confirms that of Nxumalo and Antwi (2013) that seemed to suggest human capital's emphasis on empowerment through both for- mal and informal education. Similarly, social capital (Mean=3.97: $\mathrm{SD}=1.23$ ) of farmers was deemed to be high. Though grasscutter farmers were varied in their views, they perceived the programme to have helped them in improving their livelihood capitals. (Table 4).

TABLE 4

The impact of grasscutter production technologies on grasscutter farmers' livelihoods $(N=140)$

\begin{tabular}{lll}
\hline Livelihood Type & Mean & SD \\
\hline Natural Capital & 3.75 & 1.29 \\
Physical Capital & 4.05 & 1.14 \\
Financial Capital & 4.27 & 1.02 \\
Human capital & 3.87 & 1.27 \\
Social Capital & 3.97 & 1.23 \\
Overall Mean & 3.99 & 0.77 \\
\hline
\end{tabular}

Scale: 1 = Very Low (VL), 2= Low (L), 3= Moderately High $(\mathrm{MH}), 4=\operatorname{High}(\mathrm{H}), 5=$ Very High

(VH)

\section{Conclusion and Recommendations}

The study has shown that grasscutter farmers are using the grasscutter production technologies disseminated through video in the area of study. Grasscutter farmers' use of the technologies was examined in relation to a number of socio-demographic characteristics such as age, household size and level of education. The results of the study showed that age, household size, and level of education were significantly related to use of technologies on grasscutter production. Generally, grasscutter production technologies disseminated through video in the catchment have been effective and also led to an improvement of livelihood capitals of farmers in the area of study.

Based on the findings and conclusions the following recommendations are made; 
- Farmers need to be trained regularly in the use of new technologies developed by CSIR and other research institutions through the Agricultural Information Centre.

- A wholesome dissemination approach can be beneficial to both the educated and the uneducated to facilitate better use of the technologies by the farmers in the area.

\section{REFERENCES}

Adomah Y. C. (2009) "Features and Profitability of Domestic Grasscutter Production in the Brong Ahafo Region". A thesis submitted to the School of Graduate Studies, Kwame Nkrumah University of Science and Technology, Kumasi-Ghana.

Adu, E. K. (2002) "Research on grasscutter production in Ghana". In: K. Atta-Agyepong and RitaWeidinger (Eds). Proceedings of a workshop on promoting grasscutter production for poverty reduction in Ghana.16 -18 October. Eusbett Hotel, Sunyani.

Akubuilo, C. J. C. (1982) "Adoption of Innovations among Farmers in Anambra State". Unpublished M.Sc Thesis, Department of Agricultural Economics and Extension, University of Nigeria Nsukka.

Anandajayasekeram, P. (1999) "Poverty alleviation is the issue for public agricultural research" Biotechnology and Development Monitor 40. pp 24.

Ansoms, A. \& McKay, A. (2010). A quantitative analysis of poverty and livelihood profiles: The case of rural Rwanda. Food Policy, 35, 584 -598 .

Asiabaka, C.C. \& Owens, M. (2002) "Determinants of Adoptive Behaviors of Rural Farmers in Nigeria". Proceedings of the $18^{\text {th }}$ Annual Conference of AIAEE, Durban, South Africa.
Asibey E.O.A \& Addo P. G. (2000) "The grasscutter, a promising animal for meat production". In African perspective practices and policies supporting sustainable development (Turnham D. ed.). Scandinavian seminar college Denmark, in association with Weaver press, Harare, Zimbabwe. Available: www.cdr.dk/sscafrica/as \& adgh.htm

Daudu, S., Igbashal, A. \& Ejigonoja, A. (2005) "Adoption of Innovation in Soybean Production among Farmers in Benue State". Journal of Science and Technology for Development. 1 (2), $7-15$.

Falconer, J. (1992) People's Uses and Trade in Non-Timber Forest Products in Southern Ghana: A Pilot Study. Report prepared for the Overseas Development Administration.

FAO (2001) “Agricultural and Rural Extension Worldwide. Options for Institutional Reforms in the Developing Countries". Rome. FAO. Regional Office. Accra, Ghana.

Ghana Districts (2006) "A repository of all districts in the republic of Ghana". Available at: www. ghanadistricts.com.

Igben, M.S. (1988) Farmers Capability Profile in: M. S. Igben (ed). The Nigerian Farmer and Agricultural Institution. An Assessment of NISER Ibadan, Nigeria. $657-92$.

Juma, N. \& Ondwasy, H. O. (2002) Improved management of indigenous chicken sustainable technologies contributing to the socio-economic welfare of rural household. Proc. Of the 8th Kenya Agricultural Research Institute Biennial Scientific Conference, Nairobi, Kenya. 359 - 364.

Ntiamoa-Baidu, Y. (1997) "Wildlife and food security in Africa". FAO Conservation Guide 33. Food and Agriculture Organization of the United Nations, Rome. 
Nxumalo, K. K. S. \& Antwi, M. A. (2013) "Impact of proactive land acquisition strategy on the physical capital livelihood of beneficiaries in Dr. Kenneth Kaunda District, South Africa”. Journal of Human Ecology 44 (2), 161 - 169.Available: http://www.krepublishers. com/02-Journals/.

Scoones, I. (1998) Sustainable rural livelihoods: A framework for analysis. Working Paper 72. Sustainable Livelihoods Programme. IDS. Sussex.
Tiamuyu, S. A., Akintola, J. O. \& Rahji, M. A. Y. (2009) "Technology adoption and productivity difference among growers of new rice for Africa in Savanna Zone of Nigeria".ROPICULTURA 27(4), 193-197. Available:' http://www. tropicultura.org/text/v27n4/193.pdf.

Zeba, S. (1998) "Community Wildlife Management in West Africa-A Regional Review”. Eden Series, Working Paper, No. 9. 